\title{
Comparison of Neisseria gonorrhoeae isolates from homosexual and heterosexual men
}

\author{
D FAGAN \\ From the Department of Microbiology, Wright-Fleming Institute, St Mary's Hospital Medical School, London
}

SUMMARY The gene locus known as mtr confers resistance to hydrophobic dyes, detergents, and antibiotics. It has been suggested previously that the host environment is important in the selection of gonococcal strains with this outer membrane phenotype, and thus that strains with mtr gene loci should predominate in environments high in hydrophobic molecules. Furthermore, resistance to hydrophobic molecules has been related to a sevenfold increase in a minor outer membrane protein. To test these suggestions the outer membrane phenotypes of 61 strains of Neisseria gonorrhoeae were identified using 27 rectal isolates from homosexual men and 34 urethral isolates from heterosexual men who were matched for age. The cell envelope phenotype of each strain was identified on the basis of resistance to various hydrophobic compounds. The results were compared with the protein profiles of these strains on sodium dodecyl sulphate-polyacrylamide gel electrophoresis (SDSPAGE); no significant correlation was found.

\section{Introduction}

Rectal gonorrhoea has been recognised clinically for many years, and was first described in detail in the 1930s. It was first seen in women and was, and still is, considered to be caused mainly by autoinfection from a genital infection. Several explanations were given for rectal gonorrhoea in men, but homosexual practices were not then considered to be important. It became increasingly clear, however, that rectal gonorrhoea in men was due to homosexual contact. ${ }^{1}$

The common homosexual rectal contact is between the rectum and the penis. ${ }^{1}$ The survival and growth of gonococci in the rectum is therefore essential for propagation of the organism among homosexuals. The microenvironment of the rectum is different in several respects from that of other sites that gonococci can infect. Compared with the urethra, cervix, and oropharynx, the rectum contains a large number of other bacteria $\left(10^{11} / \mathrm{g}\right.$ of the contents of the rectum $\left.{ }^{2}\right)$ and is a relatively hydrophobic environment. These differences lead to questions about the gonococci that colonise the rectum. Are they in any way specialised and selected to survive in this apparently inhospitable environment? Or are we simply seeing an epidemiological phenomenon due to homosexual

Address for reprints: Dr Dan Fagan, 78 Mallard Point, Rainhill Way, Bow, London E3

Accepted for publication 9 May 1985 practices and the associated trauma with which the gonococci are introduced into the rectum?

Certain changes in the outer surface of the gonococcus help the organism to survive in hydrophobic environments. The outer membrane of Gram negative bacteria serves as an initial barrier between the environment and the plasma membrane. Several components of the outer structure of the gonococcus are important in its interaction with the environment and the host. These include lipopolysaccharide, pili, outer membrane proteins, and possibly a capsule. Several workers have suggested that the outer membrane proteins are most important for resistance to hydrophobic environments. ${ }^{34}$

The outer membrane of gonococci, like that of other Gram negative bacteria, is composed of lipopolysaccharide, protein, and phospholipid. Of the three major proteins (I, II, and III), protein I is the most abundant and is present in all gonococci. It forms polymers that span the outer membrane to form large aqueous pores with diameters of $2.5 \mathrm{~nm}$, which are thought to be largely responsible for the greater sensitivity of gonococci than other Gram negative organisms to hydrophilic antibiotics, such as penicillin, tetracycline, and chloramphenicol. ${ }^{56}$ Gonococci are also very sensitive to certain hydrophobic dyes, antibiotics, and detergents, which are thought to penetrate membranes by dissolving in the phospholipid bilayer.

Low level resistance of Neisseria gonorrhoeae to 
hydrophobic molecules has been known for some time to be determined by certain genetic loci (pen A, pen B, and $\mathrm{mtr}),{ }^{7}$ which function in a cumulative manner. Another locus, env, determines an increased sensitivity to the same reagents. ${ }^{8}$ Phenotypically, env seems to be the opposite of $\mathrm{mtr}$, and is dominant if both are present. Clinical isolates bearing env often show repressed mtr. Mutations at these loci have been induced experimentally by ultraviolet irradiation mutagenesis and have been found in clinical isolates. ${ }^{49}$ Acquisition of $\mathrm{mtr}$, which results in low level, nonspecific, increased resistance to hydrophobic molecules and drugs, has been reported to be accompanied by a sevenfold increase in the amount of a minor outer membrane protein, the apparent subunit molecular weight (ASMW) of which is 52000 , and a $32 \%$ increase in peptidoglycan cross linking, but no change in lipopolysaccharide or phospholipid. ${ }^{3}$

The interaction between the gonococcal outer membrane and hydrophobic molecules has been shown to be related to the degree of exposure of the phosopholipid head groups, which is controlled by the presence of a glycosolated outer membrane component. Masking of the phospholipid head groups by this component results in resistance to the hydrophobic molecules. ${ }^{6}$ The suggestion that the nature and concentration of hydrophobic molecules at different sites of infection (such as the urethra, rectum, cervix, or oropharynx) would lead to the selection of certain strains at certain sites has been validated by the work of Morse et $a{ }^{4}$ and Janda et al. ${ }^{10}$

In the study published here I aimed to compare the results obtained from different groups of patients in the United States of America with those from patients attending the sexually transmitted disease (STD) clinic at this hospital. The study consisted of two main parts: measuring the minimum inhibitory concentrations (MICs) of erythromycin, fusidic acid, and Tritron $\mathrm{X}-100$ for each strain of $\mathbf{N}$ gonorrhoeae to establish its cell envelope phenotype, and conducting sodium dodecyl sulphate-polyacrylamide gel electrophoresis (SDS-PAGE) on whole cell extracts of most strains to compare protein patterns with phenotypes ascribed by MIC and to compare sites of isolation of strains. SDSPAGE was also conducted on outer membrane preparations of a few strains.

\section{Patients, materials, and methods}

\section{STUDY POPULATION}

The strains of $\mathbf{N}$ gonorrhoeae used in this study were collected from patients attending the STD clinic at this hospital between 3 March and 11 April 1983. Rectal isolates were taken from 27 men giving a history of homosexual contact only. Urethral isolates were taken from 34 men giving a history of heterosexual contact only. All isolates were grown on GC agar base (Difco, East Molsey, Surrey, England) supplemented with $1 \%$ IsoVitalex (BBL, Cockeysville, United States of America).

IDENTIFYING PHENOTYPES OF CELL ENVELOPES The phenotype of the cell envelope of each strain was identified by the method of Morse et al ${ }^{4}$ to measure its resistance or sensitivity to various hydrophobic molecules. The MIC of erythromycin, fusidic acid, and Tritron $\mathrm{X}-\mathbf{1 0 0}$ for all strains was measured using an agar dilution method. In each case an inoculum of $10^{3}$ to $10^{4}$ colony forming units (cfu) was incubated for 48 hours at $36^{\circ} \mathrm{C}$ in $6 \%$ carbon dioxide.

\section{SEPARATION OF PROTEINS}

Proteins were separated by the SDS-PAGE method of Lamelli" ${ }^{11}$ using $5 \%$ stacking gels and $12 \cdot 5 \%$ separating gels. Whole cell preparations were adjusted to $2 \mathrm{~g} / 1$ protein ${ }^{12}$ and taken up in a sampling buffer of $2 \%$ SDS, $0 \cdot 1 \mathrm{~mol} / 1$ trometamol (TRIS)-hydrochloric acid pH 6.8, $10 \%$ glycerol, $0 \cdot 01 \%$ bromophenol blue, and $0.1 \mathrm{~mol} / \mathrm{l}$ Cleland's reagent (dithiothreitol). Samples were heated at $100^{\circ} \mathrm{C}$ for five minutes. Gels were stained with $0 \cdot 1 \%$ Coomassie brilliant blue (R250; Sigma, Poole, Dorset, England).

\section{ISOLATION OF OUTER MEMBRANE PROTEIN COMPLEXES}

Outer membrane protein complexes were isolated by the lithium acetate extraction method described by Heckels. ${ }^{13}$ The protein pellet was resuspended in sampling buffer at a concentration of $1 \mathrm{~g} / \mathrm{l}$ and boiled for five minutes with $0.1 \mathrm{~mol} / 1$ dithiothreitol. A volume of $30 \mu \mathrm{l}$ was then placed on an SDS polyacrylamide gel as described above.

\section{Results}

\section{STUDY POPULATION}

The patients from whose rectums $N$ gonorrhoeae was isolated were matched for age with patients with urethral gonorrhoea. Some American workers have studied patients who had not received antibiotics for their current infections, ${ }^{4}$ but I did not study such patients as it was impractical.

\section{CELL ENVELOPE PHENOTYPE}

Strains were considered to be mtr mutants if the MIC of erythromycin was $\geqslant 2 \mathrm{mg} / \mathrm{l}$, the MIC of fusidic acid was $\geqslant 0.5 \mathrm{mg} / \mathrm{l}$ and the MIC of Tritron X-100 was $\geqslant$ $2 \mathrm{mg} / \mathrm{ml}$. The others were described as wild type strains. Table I shows that the number of mtr mutants in rectal isolates was significantly $\left(\chi^{2}=12 \cdot 2\right.$, p $<0.001)$ greater than the number in urethral isolates. 
TABLE I Number (\%) of mtr mutants in rectal and urethral isolates from 61 men

\begin{tabular}{lcc}
\hline & Mtr mutants & Wild type \\
\hline Rectal isolates $(\mathrm{n}=27)$ & $16(59 \cdot 3)$ & $11(40 \cdot 7)$ \\
Urethral isolates $(\mathrm{n}=34)$ & $6(17 \cdot 6)$ & $28(82 \cdot 4)$ \\
Total $(\mathrm{n}=61)$ & $22(36 \cdot 1)$ & $39(63 \cdot 9)$ \\
\hline
\end{tabular}

SDS-PAGE WHOLE CELL PREPARATIONS

Table II shows the results seen before the gels were dried. No differences were apparent between $\mathrm{mtr}$ mutants and wild type strains, or between rectal and urethral isolates. Unfortunately, a technical error during the drying process made it impossible to mount

TABLE II Number (\%) of mtr mutants in rectal and urethral isolates from 46 men examined by sodium dodecyl sulphatepolyacrylamide gel electrophoresis (SDS-PAGE)

\begin{tabular}{lcl}
\hline & Mtr mutants & Wild type \\
\hline Rectal isolates $(\mathrm{n}=23)$ & $11(47 \cdot 8)$ & $12(52 \cdot 2)$ \\
Urethral isolates $(\mathrm{n}=23)$ & $5(21 \cdot 7)$ & $18(78 \cdot 3)$ \\
Total $(\mathrm{n}=46)$ & $16(34 \cdot 8)$ & $30(65 \cdot 2)$ \\
\hline
\end{tabular}

or photographically reproduce the gels. Protein I was similar in all isolates (though different percentage gels would be required for closer examination of proteins I, II, and III).

\section{OUTER MEMBRANE PREPARATIONS}

Outer membranes were prepared from five strains: three wild type, and two mtr mutants. The outer membrane preparations also showed no differences between the mtr mutant and wild type strains, even in repeat experiments with double the concentration of protein.

\section{Discussion}

The results show that there was a clear cut difference between the strains isolated from the rectums and the urethras in terms of resistance to hydrophobic molecules and antibiotics. The results not only confirm previous studies, but are in fact much more striking. Morse et al found a total of $12.5 \% \mathrm{mtr}$ mutants compared with $36 \cdot 1 \%$ in this study. ${ }^{4}$ This difference probably reflects differences in the selection of the study population. Whereas other workers used a broad range of isolates, in this study the two extremes of the range were used - that is, rectal isolates from exclusively homosexual patients (from information in the clinical notes) and urethral isolates from patients known to have only female sexual contacts. I did not study intermediary points on the range, such as urethral isolates from homosexual patients, patients with both female and male sexual contacts, or female patients. More clear cut results were therefore obtained.

Though there appears to be a clear difference between the cell envelope phenotypes of the two groups studied, there was no correlation between the resistant phenotype and the acquisition of any outer membrane proteins and no evidence of an increase in a $52000 \mathrm{ASMW}$ protein, as has been strongly suggested by several American workers. ${ }^{34}$ The resistance of $\mathrm{mtr}$ mutants in this study was therefore not clearly related to this or any other protein associated with the outer membrane alone, or with the whole cell.

If protein is not implicated, another mechanism for resistance needs to be found. Resistance to hydrophobic molecules is probably related to masking the phospholipid component of the outer membrane, through which hydrophobic molecules gain entry to the cell. The glycosylated component of Lysko and Morse appears to provide such masking. ${ }^{6}$ The nature of this component is at present not known, but if it is not a protein the phospholipid head groups themselves are possibly glycosylated.

Alterations in the cross linking of the peptidoglycan due to mtr mutation, which non-specifically affects resistance, may well have secondary effects, or may be secondary effects of changes in cell envelope structure that are as yet unknown. It cannot be said whether these changes in cross linking have any effect on sensitivity to antibiotics, but it would seem to be more likely that such changes are the mechanisms of mutations specifically affecting resistance to penicillin at loci such as pen $A$ and pen $B$.

The study by Morse et al showed an interesting association of mtr mutants with a certain serotype of protein $\mathrm{I} .{ }^{4}$ Gonococci can be placed into three groups, WI, WII, and WIII, on the basis of serological reactions due to protein $\mathrm{I} .{ }^{14} \mathrm{Of}$ the $19 \mathrm{mtr}$ mutants in the study of Morse et al, 17 (89.5\%) were of serotype WII. ${ }^{4}$ The implication that differences in protein I may affect resistance or sensitivity of the gonococci is another interesting possibility. Unfortunately the facilities for serotyping the strains used in this study were not available, and the gels used for protein separation were unsuitable for close scrutiny of small differences in protein I.

Auxotyping has been used as a method of defining gonococcal populations. Except in the case of disseminated gonococcal infections, however, which are strongly associated with strains requiring arginine, hypoxanthine, and uracil (AHU auxotype), ${ }^{15}$ auxotyping is proving to be of little use as an epidemiological tool. Studies comparing mtr mutants and their auxotypes have not yet been conducted. 
Many of the detailed facts about the biochemical analysis of mtr mutants quoted here have been taken from sources that obtained the data using strains that apparently possess the $\mathbf{5 2} 000$ ASMW protein. It is possible, of course, that the discrepancy does not stop with outer membrane proteins, and that the resistant strains studied in this project result from a different mutation. Thus some of the facts quoted may not be relevant. Nevertheless, it seems unlikely that one or more of the alternatives suggested above is not, at least in part, the mechanism of resistance.

I thank Dr C A Ison for help and encouragement provided during the period of this study.

This paper won the Student Prize of the Medical Society for the Study of Venereal Diseases in 1985.

\section{References}

1. Willcox RR..The rectum as viewed by the venereologist. British Journal of Venereal Diseases 1981;57:1-6.

2. Jawetz E, Melnick JL, Adelberg EA. Review of medical microbiology. Los Altos, California: Lange Medical Publications, 1972:248.

3. Guymon LF, Walstad DL, Sparling PF. Cell envelope alterations in antibiotic-sensitive and resistant strains of Neisseria gonorrhoeae. J Bacteriol 1978;136:391-401.
4. Morse SA, Lysko PG, McFarland L, et al. Gonococcal strains from homosexual men have outer membranes with reduced permeability to hydrophobic molecules. Infect Immun 1982;37:432-8.

5. Blake MS, Gotschlich EC. Gonococcal membrane proteins: speculation on their role in pathogenesis. Prog Allergy 1983;33:298-313.

6. Lysko PG, Morse SA. Neisseria gonorrhoeae cell envelope: permeability to hydrophobic molecules. J Bacteriol 1981;45:946-52.

7. Sparling PF, Sarubbi FA, Blackman E. Inheritance of low-level resistance to penicillin, tetracycline, and chloramphenicol in Neisseria gonorrhoeae. J Bacteriol 1975;124:740-9.

8. Sarubbi, FA, Sparling PF, Blackman E, Lewis E. Loss of lowlevel antibiotic resistance in Neisseria gonorrhoeae due to env mutations. J Bacteriol 1975;124:750-6.

9. Eisenstein BI, Sparling PF. Mutations to increased antibiotic sensitivity in naturally occurring gonococci. Nature 1978;271:242-4.

10. Janda WM, Morello JA, Lerner SA, Bohnhoff M Characteristics of pathogenic Neisseria spp isolated from homosexual men. J Clin Microbiol 1983;17:85-91.

11. Lamelli UK. Cleavage of structural proteins during the assembly of the head bacteriophage T4. Nature 1970;227:680-5.

12. Lowry OH, Rosebrough NJ, Ferr AL, Randall RJ. Protein measurement with the folin phenol reagent. $J$ Biol Chem 1951;193:265-75.

13. Heckels JE. The surface properties of Neisseria gonorrhoeae. Isolation of the major components of the outer membrane. $J$ Gen Microbiol 1977;99:333-41.

14. Sandstrom EG, Danielsson D. Serology of Neisseria gonorrhoeae. Classification with co-agglutination. Acta Pathol Microbiol Scand [B] 1980;88:27-38.

15. Knapp JS, Holmes KK. Disseminated gonococcal infections caused by Neisseria gonorrhoeae with unique nutritional requirements. $J$ Infect Dis 1975;132:204-8. 